\title{
Precision and accuracy of Morgan ventilometers at continuous and sinusoidal flows
}

\author{
J.D. Hart, R.T. Withers, R.C. Tucker
}

Precision and accuracy of Morgan ventilometers at continuous and sinusoidal flows. J.D. Hart, R.T. Withers, R.C. Tucker. CERS Journals Ltd 1994.

ABSTRACT: The P.K. Morgan Mark II Ventilometer comprises a turbine transducer and a control/readout unit, which contains either a VENTX5A or VENTX6A programme. This equipment is used to measure minute ventilation during oxygen consumption tests. The precision and accuracy of six of these devices (a VENTX5A with two turbines, and two VENTX6As each with two different turbines) were examined during continuous and pulsatile flows; accuracy was affected by the syringe rate during the calibration procedure. The reference standard was a $350 l$ Collins chain-compensated gasometer.

At continuous flows, the two VENTX5A devices showed accuracies of 99.5-100.5\% over the range 60-160 $l \cdot \mathrm{min}^{-1}$ whereas those for the four VENTX6As were 99.3-102.1\% over the range 60-200 l$\cdot \mathrm{min}^{-1}$. The mean accuracies of sinusoidal flows for the VENTX5A ranged between 96.1-101.3\% for minute volumes spanning 15-200 $l \cdot \mathrm{min}^{-1}$; comparable data for the VENTX6As were 95.9-98.9\%. These mean accuracies improved to $98.1-101.3 \%$ for the VENTX5A at measured minute volumes $>80 l \cdot \mathrm{min}^{-1}$. Omission of the two lowest tidal volumes ( 1 and $1.5 l$ ) for the VENTX6As narrowed the range of accuracy to $96.9-98.5 \%$. The coefficients of variation for five trials at each minute ventilation were $0-0.2 \%$.

We conclude that, while the P.K. Morgan Mark II Ventilometer has excellent precision, its accuracy is dependent on the calibration syringe rate, minute ventilation and programe.

Eur Respir J, 1994, 7, 813-816.

The determination of oxygen consumption $\left(\dot{\mathrm{V}}_{2}\right)$ involves the accurate measurement of gas volume. A perfect device for this measurement would be unaffected by the composition, turbulence, density, viscosity, temperature, water vapour content and flow waveform of the gas. As the currently available measurement principles are all, to some extent, influenced by these factors, it is not possible to easily and accurately measure gas volume to research tolerances of $\pm 2 \%[1,2]$. The importance of the volume measuring device is highlighted by the fact that if it under- or over-reads by $5 \%$ then the $\dot{\mathrm{VO}}_{2}$ will be in error by an identical amount.

The P.K. Morgan Ventilometer (P.K. Morgan Ltd, Rainham, Kent, UK) contains a low dead-space turbine gas volume measurement device that possesses the unusual characteristic of being easily calibrated using a pulsatile flow (four strokes of a $1 l$ handheld calibration syringe [3]). The resultant hexadecimal calibration factor $(8 \mathrm{~F}=143$; i.e. $8 \times 16+15)$ is then entered into the control/readout unit to electronically compensate for intraand inter-turbine variability. The aims of this study were, therefore, to determine the accuracy of the P.K. Morgan Ventilometer (large turbine: VENTX5A and VENTX6A programmes) against the reference standard of a $350 l$ Collins chain-compensated gasometer (Warren E. Collins,
Exercise Physiology Laboratory, School of Education, The Flinders University of South Australia, Bedford Park, South Australia.

Correspondence: J.D. Hart

Exercise Physiology Laboratory

School of Education

The Flinders University of South Australia Bedford Park

South Australia 5042

Keywords: Calibration factors large turbine

resistance

volume measuring device

Received: December 161992

Accepted after revision November 41993
Braintree, MA, USA) using the following gas compositions and waveforms:

1) Continuous flows of water vapour saturated air at rates from 55 to $200 l \cdot \mathrm{min}^{-1}$ which simulated the measurement of mixed expirate withdrawn from Douglas Bags [4].

2) Sinusoidal flows with combinations of tidal volume and frequency which mimicked adult respiration during exercise. Ambient air was aspirated through the meter to duplicate the inspiratory limb of a breathing circuit.

\section{Materials and methods}

\section{Percentage accuracy and flow resistance test circuits}

The gas circuit for the continuous flow tests was: 150 $l$ of saturated atmospheric air in the $350 l$ gasometer; $0.8 \mathrm{~m}$ of $3.8 \mathrm{~cm}$ ID corrugated plastic tubing; P K Morgan Ventilometer; R2700 respiratory valve without leaflets (Hans Rudolph, Kansas City, MO, USA); $0.8 \mathrm{~m}$ of 3.8 $\mathrm{cm}$ ID corrugated plastic tubing connected to the expiratory port of the respiratory valve; and a vacuum pump. A sensor [5] in the respiratory valve measured the 
temperature of the gas passing through the turbine. Prior to each test, the gasometer was filled with atmospheric air saturated with water vapour by connecting a heated waterbath humidifier (Model Z3280, Fisher \& Paykel, Auckland, NZ) to the inlet tap. The pressure drop across the respiratory valve-turbine unit during each test was measured by an incline-plane water manometer. The devices were tested at flows from 55 to $180-200 \mathrm{l} \cdot \mathrm{min}^{-1}$. Slower flows were not studied, as they would generally not be used with the Douglas Bag technique.

The gas circuit for the sinusoidal flow tests was: atmospheric air through the P.K. Morgan Ventilometer; R2700 respiratory valve with leaflets; sinusoidal piston pump connected to the respiratory valve's mouthpiece; and 0.8 $\mathrm{m}$ of $3.8 \mathrm{~cm}$ ID corrugated plastic tubing from the respiratory valve's outlet to the $350 l$ gasometer. Each test passed $300 l$ of gas. Flow waveforms for exercising adults were simulated by the sinusoidal piston pump, using all combinations of $1.0,1.5,2.1,2.6$ and $3.1 l$ tidal volumes and $15,25,35,45,55$ and $65 \mathrm{~b} \cdot \mathrm{min}^{-1}$ stroke frequencies. These were equivalent to minute volumes from 16 to $220 l \cdot \mathrm{min}^{-1}$ at body temperature, ambient pressure and saturated with water vapour (BTPS). The temperature of the gas passing through the Ventilometer's turbine and that in the $350 l$ gasometer were monitored to within $0.1^{\circ} \mathrm{C}$ [5]. Atmospheric pressure was measured with a mercury column barometer (Casella, London, UK) and was corrected for the effect of temperature on mercury expansion. The R2700 respiratory valve and P.K. Morgan turbine assembly was checked for entrainment. This occurs when a rapidly decelerating gas column on the expiratory limb draws an additional volume through the valve and turbine that does not pass through the flow generator (sinusoidal piston pump or human subject). There was no gas leak of this type for any of the flow waveforms [6].

\section{Test protocols}

Percentage Accuracy. The continuous and sinusoidal flow circuits were used to determine the accuracy of each turbine-programme combination. The Ventilometers were calibrated in accordance with the manufacturer's instructions [3] prior to the six trials for each tidal volume. These calibrations were conducted with the P.K. Morgan turbine and $0.8 \mathrm{~m}$ of $3.8 \mathrm{~cm}$ ID corrugated plastic tubing attached to the inspiratory and expiratory ports, respectively, of an R2700 respiratory valve. The total range of the calibration factors was approximately \pm 1 hexadecimal unit about a most common calibration factor, except for one VENTX5A-turbine combination which repeatedly read either 86 or $8 \mathrm{~A}$.

Effect of calibration factor on precision and accuracy. During the preceding percentage accuracy tests, we discovered that the hexadecimal calibration factor increased with the calibration syringe stroke rate. The effect of this on the accuracy of volume measurement using one VENTX5A with two turbines and one VENTX6A with a different turbine was then tested, using five separate calibration factors at each of four sinusoidal waveforms which spanned the range from light to maximal exercise $\left(1.5 l \times 15 \mathrm{~b} \cdot \mathrm{min}^{-1}, 2.1 \mathrm{l} \times 25 \mathrm{~b} \cdot \mathrm{min}^{-1}, 2.6 l \times 35 \mathrm{~b} \cdot \mathrm{min}^{-1}\right.$ and $\left.3.1 l \times 55 \mathrm{~b} \cdot \mathrm{min}^{-1}\right)$. Three of the calibration factors were determined by passing the $4 \times 1 l$ syringe strokes at typical rates of 15,30 and $45 \mathrm{~b} \cdot \mathrm{min}^{-1}$. The other two calibration factors of 81 and $9 \mathrm{~F}$ are the extreme values delineated by the manufacturer [3]. Five trials were conducted in order to examine the precision (reproducibility) with which a programme-turbine combination measured these sinusoidal waveforms. The effect of the three syringe stroke rates on the measurement of continuous flows (50, 100, 150 and $\left.190 \mathrm{l} \cdot \mathrm{min}^{-1}\right)$ by a VENTX5A programme was also examined.

\section{Results}

\section{Percentage accuracy tests}

Except for one data point $(99.3 \%$ accuracy for one device at $\left.70 l \cdot \mathrm{min}^{-1}\right)$, both VENTX5A combinations read within $\pm 0.5 \%$ of the criterion for continuous flows over the range $60-160 l \cdot \mathrm{min}^{-1}$. The four VENTX6A combinations yielded errors of -0.7 to $+2.1 \%$ over the range 60-200 $l \cdot \mathrm{min}^{-1}$.

The mean percentage accuracies at sinusoidal flows are portrayed in figures 1 and 2. The two VENTX5A combinations yielded accuracies from $96.1-102.8 \%$ and 96.0-101.1\%, respectively; the means for these two combinations are shown graphically in figure 1 . The five tidal volumes in this figure were all within $3 \%$ of one another at any one flow rate, and it is noticeable that the percentage accuracy (Morgan Ventilometer volume/

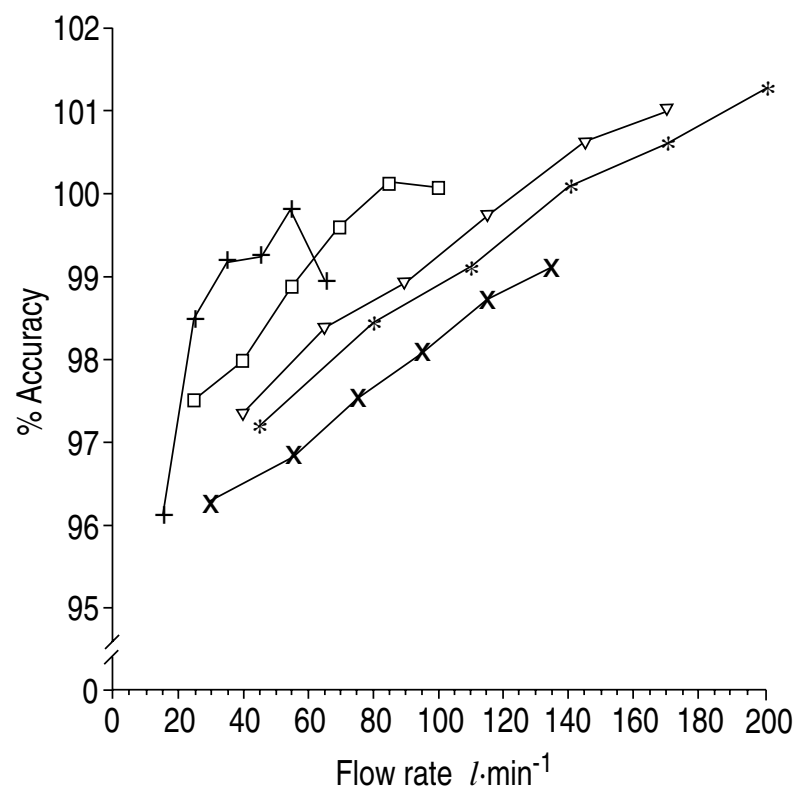

Fig. 1. - Mean accuracy at sinusoidal flows for one P.K. Morgan Ventilometer (VENTX5A) and two turbines, \% accuracy=(Morgan Ventilometer volume/reference volume) $\times 1.0+$ : $1.0 l \times 15-65$ b. $\min ^{-1} ;-\square-: 1.5 l \times 15-65 \mathrm{~b} \cdot \mathrm{min}^{-1} ;-\mathrm{x}: 2.1 \mathrm{l} \times 15-65 \mathrm{~b} \cdot \mathrm{min}^{-1} ; \boldsymbol{\nabla}$. $2.6 l \times 15-65 \mathrm{~b} \cdot \mathrm{min}^{-1} ;-*-3.1 \mathrm{l} \times 15-65 \mathrm{~b} \cdot \mathrm{min}^{-1}$. 


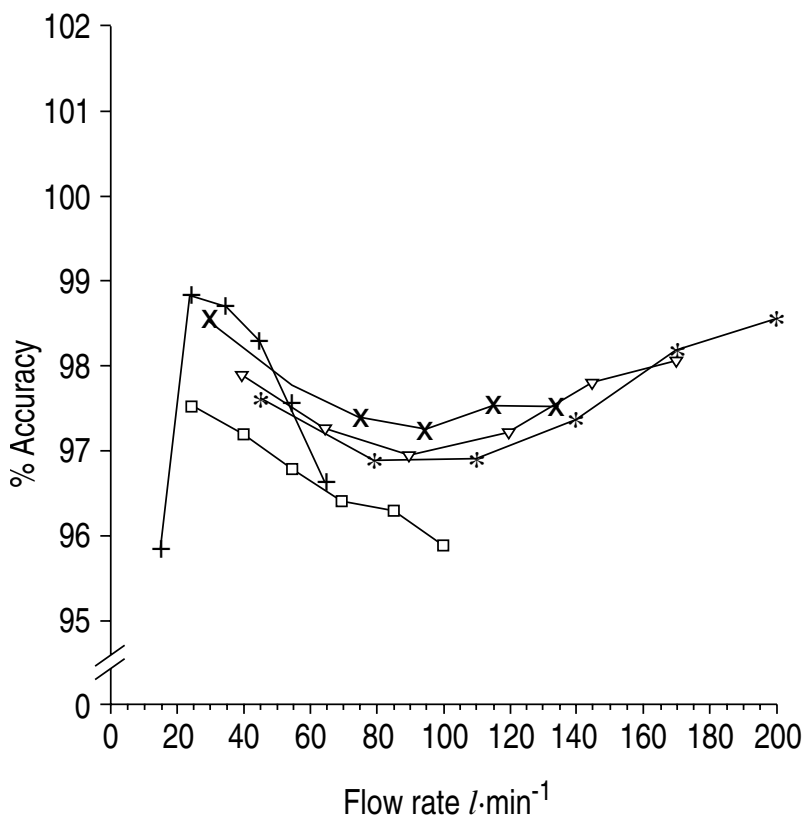

Fig. 2. - Mean accuracy at sinusoidal flows for two P.K. Morgan Ventilometers (VENTX6A) each with two different turbines. \% accuracy $=($ Morgan Ventilometer volume/reference volume $) \times 100 .+: 1.0 \mathrm{l}$ $\times 15-65 \mathrm{~b} \cdot \mathrm{min}^{-1} ;-\square-: 1.5 l \times 15-65 \mathrm{~b} \cdot \mathrm{min}^{-1} ; \times-: 2.1 l \times 15-65 \mathrm{~b} \cdot \mathrm{min}^{-1}$; $\boldsymbol{\nabla}: 2.6 l \times 15-65 \mathrm{~b} \cdot \mathrm{min}^{-1} ;-*-: 3.11 \times 15-65 \mathrm{~b} \cdot \mathrm{min}^{-1}$.

reference volume $\times 100$ ) increased with flow rate. Figure 1 also confirms that mean accuracy spread improved to $98.1-101.3 \%$ at measured minute volumes $>80 \mathrm{l} \cdot \mathrm{min}^{-1}$. By comparison, the VENTX6A means in figure 2 exhibit a smaller range of accuracy at each flow rate, and this was supported by the data of individual devices. The mean accuracy of $95.9-98.9 \%$, furthermore, remained relatively unaffected by the flow rate, but was narrowed to $96.9-98.5 \%$ by omission of the two lowest tidal volumes.

\section{Calibration factor effect on precision and accuracy}

The mean percentage accuracies of five trials per waveform at each of three calibration rates and the two extremes are presented in table 1 . These data indicate that the reading decreased as the calibration rate increased; the greatest accuracy was achieved with calibration rates of 30 and $45 \mathrm{~b} \cdot \mathrm{min}^{-1}$. The coefficients of variation for each of the 60 cells in table 1 ranged between $0-0.2 \%$.

\section{Flow resistance}

One turbine was tested with a continuous flow of 300 $l \cdot \mathrm{min}^{-1}$ and gave a resistance of $0.1 \mathrm{kPa} \cdot l^{-1} \cdot \mathrm{s}$.

\section{Discussion}

\section{Percentage accuracy tests}

Figures 1 and 2 emphasize that a change in sinusoidal waveform for a given minute volume affected the mean accuracy of the VENTX5A more than that of the VENTX6A. This was supported by the mean data spreads for these two programme-turbine combinations of $5.9 \%$ and $3.8 \%$, respectively. These figures, furthermore, show that an increasing minute volume altered the VENTX5A's mean percentage accuracy $(96.1-101.3 \%)$ by more than that for the VENTX6A (95.9-98.9\%).

During these tests, we became aware of the effect of calibration rate on accuracy. The data in table 1 , which are discussed in the next section, therefore suggest that the calibration rate for figures 1 and 2 was about 45 $\mathrm{b} \cdot \mathrm{min}^{-1}$.

\section{Effect of calibration factor on precision and accuracy}

The very low coefficients of variation ( 0 to $0.2 \%$ ) for the five trials at each waveform demonstrated excellent precision for the ventilometers over a range of calibration factors. The positive relationship between calibration rate and calibration factor was confirmed during both continuous and sinusoidal flow tests and by comparing

Table 1. - Effect of calibration factor on the accuracy* of three Morgan Ventilometers during sinusoidal flows**

\begin{tabular}{|c|c|c|c|c|c|c|c|c|c|c|c|c|c|c|c|}
\hline \multirow{3}{*}{$\begin{array}{l}\text { Calibration } \\
\text { rate b.min }{ }^{-1} \\
\text { Calibration } \\
\text { factor }\end{array}$} & \multicolumn{5}{|c|}{ 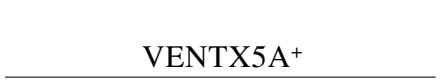 } & \multicolumn{5}{|c|}{$\begin{array}{l}\text { Programme } \\
\text { VENTX5A }^{+}\end{array}$} & \multicolumn{5}{|c|}{ VENTX6A $^{+}$} \\
\hline & $\#$ & 15 & 30 & 45 & $\#$ & $\#$ & 15 & 30 & 45 & $\#$ & $\#$ & 15 & 30 & 45 & $\#$ \\
\hline & 81 & 82 & 86 & $8 \mathrm{~A}$ & $9 \mathrm{~F}$ & 81 & 86 & 89 & $8 \mathrm{C}$ & $9 \mathrm{~F}$ & 81 & 90 & 93 & 96 & $9 \mathrm{~F}$ \\
\hline $\begin{array}{l}1.5 \mathrm{l} \times \\
15 \mathrm{~b} \cdot \mathrm{min}^{-1}\end{array}$ & 104.3 & 103.5 & 100.4 & 97.4 & 84.5 & 106.9 & 102.9 & 100.6 & 98.5 & 86.7 & 115.3 & 103.3 & 100.9 & 99.0 & 93.5 \\
\hline $\begin{array}{l}2.1 \mathrm{l} \times \\
25 \mathrm{~b} \cdot \mathrm{min}^{-1}\end{array}$ & 106.2 & 105.2 & 102.6 & 99.7 & 86.1 & 107.5 & 103.3 & 101.1 & 99.1 & 87.3 & 114.6 & 102.7 & 100.7 & 98.6 & 93.1 \\
\hline $\begin{array}{l}2.6 \mathrm{l} \times \\
35 \mathrm{~b} \cdot \mathrm{min}^{-1}\end{array}$ & 108.0 & 106.7 & 103.5 & 100.6 & 87.6 & 108.9 & 104.5 & 102.0 & 99.9 & 88.2 & 114.2 & 102.2 & 100.1 & 98.1 & 92.5 \\
\hline $\begin{array}{l}3.1 \mathrm{l} \times \\
55 \mathrm{~b} \cdot \mathrm{min}^{-1}\end{array}$ & 110.2 & 108.8 & 105.5 & 102.5 & 89.3 & 111.1 & 106.7 & 104.1 & 101.8 & 90.2 & 115.3 & 103.0 & 101.0 & 99.0 & 93.4 \\
\hline
\end{tabular}

$*: \%$ accuracy $=($ Morgan Ventilometer volume/reference volume $) \times 100 ; * *$ : each of the 60 cells represents the mean of five trials; +: different turbines used in each test series; \#: no calibration rate, since the ventilometers were arbitrarily set at 81 and $9 \mathrm{~F}$, which are the extreme calibration factors delineated by the manufacturer. 
the two extreme calibration factors specified by the manufacturer (see table 1). These tests demonstrated that an increase of one unit in the hexadecimal calibration factor produced a 0.6 to $0.9 \%$ decrease in sinusoidal flow reading. Furthermore, the continuous flow test data (not shown) also emphasized a virtually identical 0.7 to $1.0 \%$ decrease in reading per hexadecimal unit increase in calibration factor. The dependency of the ventilometer's accuracy on the calibration rate severely limited the validity of the calibration procedure.

\section{Flow Resistance}

The pressure differential of $0.5 \mathrm{kPa}$ across the tested turbine at $300 l \cdot \mathrm{min}^{-1}$ (continuous flow, equivalent to a resistance of $\left.0.1 \mathrm{kPa} \cdot l^{-1} \cdot \mathrm{s}\right)$ was within the $0.6 \mathrm{kPa}$ limit recommended by JONES and CAMPBELL [7].

Acknowledgements: The authors acknowledge the financial assistance of the Australian Sports Commission and the Asthma Foundation of South Australia.

\section{References}

1. Clausen JL, ed. Pulmonary Function Testing Guidelines and Controversies. Equipment, Methods and Normal Values. 1982; New York, Academic Press, p. 80.

2. Gardner R, Hawkinson JL, West BJ. Evaluating commercially available spirometers. Am Rev Respir Dis 1980; 121: 73-82.

3. P.K. Morgan Instruments Ltd. Operating Instructions for Ventilometer Mark 2. 1983; Rainham, Kent, England.

4. Wilmore JH, Costill DL. Semi-automated systems approach to the assessment of oxygen uptake during exercise. J Appl Physiol 1974; 36: 618-620.

5. Gore CJ, Withers RT, Woods G, Day L. Inexpensive probes for the determination of body temperature. $\mathrm{Br} \mathrm{J}$ Sports Med 1987; 21: 127-129.

6. Hart JD. Calibration of gas volume measuring devices with continuous and pulsatile flows. Unpublished B.Ed. (P.E.) Honours degree thesis. 1989; The Flinders University of South Australia.

7. Jones NL, Campbell EJM. Clinical Exercise Testing, 2nd edn. 1982; Philadelphia, W.B. Saunders Co., p.214. 